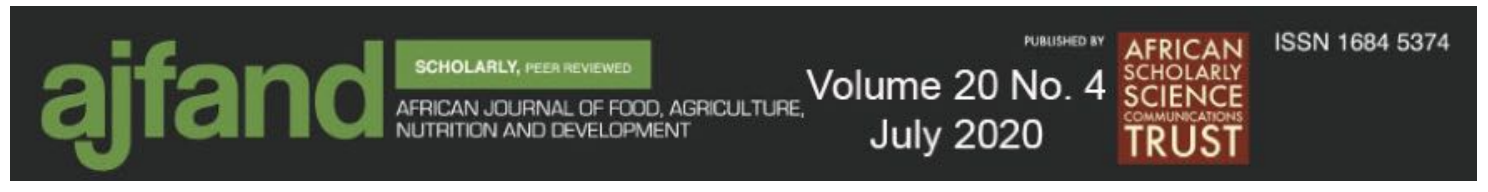

Afr. J. Food Agric. Nutr. Dev. 2020; 20(4)16261-16277

https://doi.org/10.18697/ajfand.92.17805

\title{
COUSCOUS MANUFACTURE IN FLUIDIZED BED BY WET AGGLOMERATION OF WHEAT SEMOLINA
}

$$
\text { Soulimani } \mathrm{O}^{1 *} \text {, Dounit } \mathrm{S}^{1} \text { and } M \text { Bouhadda }{ }^{\Upsilon}
$$

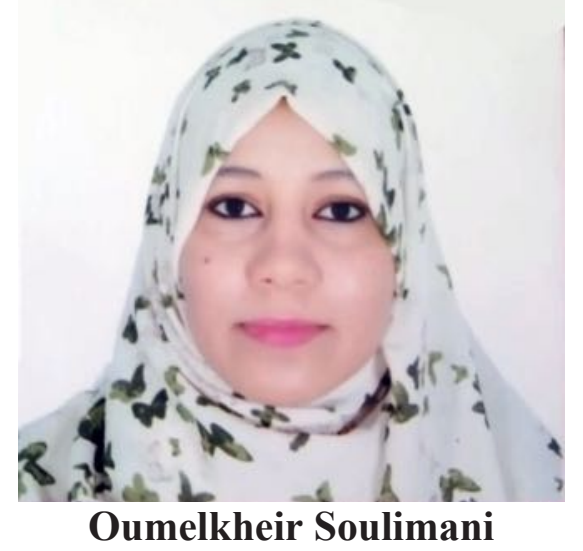

*Corresponding author email address: soulimani2013@gmail.com

${ }^{1}$ Univiversity of Ouargla, Faculty of Applied Sciences, Lab. Process Engineering, Ouargla, Algeria 


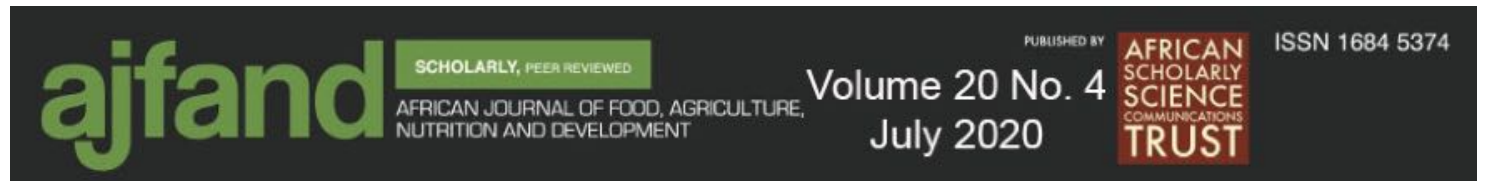

\begin{abstract}
Agglomeration is a key unitary operation in a number of industries (pharmaceutical, chemical, food, civil engineering). The agglomeration process controls the structural characteristics and final properties of agglomerates. One of the activities involving food agglomeration is the production of couscous by agglomeration of durum wheat semolina. Couscous is considered the most important traditional dish among the Maghreb people. The industrial process of couscous production includes various stages, the most important of which is wet granulation of semolina, which contributes to the quality of the final product. The agglomeration of cereal powders from different origins (durum wheat, maize and barley) has been performed in a variety of equipment such as high shear mixers, drum mills and fluidized beds. However, the agglomeration of semolina in fluidized beds has had very limited study. The purpose of this research is, therefore, to study couscous production using durum wheat semolina in a fluidized bed equipped with a spray nozzle. The fluidized bed has the advantage of generating strong particle movement and intense mixing to increase the size of the granules evenly throughout the mass used.The efficiency of this process is determined by the couscous yield defined as the mass ratio of couscous to raw material. The results showed that couscous can be produced from semolina by wet fluidized bed agglomeration with a specific effect of fluidification air flow, liquid flow, bed temperature and spray liquid properties on the couscous quality (size, brittleness and morphology) as well as on yield. The latter rose by $60 \%$ when the water containing flour was sprayed. Furthermore, the results of this study showed that granules size changes directly with the liquid flow rate, while temperature and air flow have an opposite effect. It was also found that changing binder components have an effect on the quality of the agglomeration of the product.
\end{abstract}

Key words: Couscous, agglomeration, fluidization, semolina, friability, granulation, atomization, size enlargement, drying 


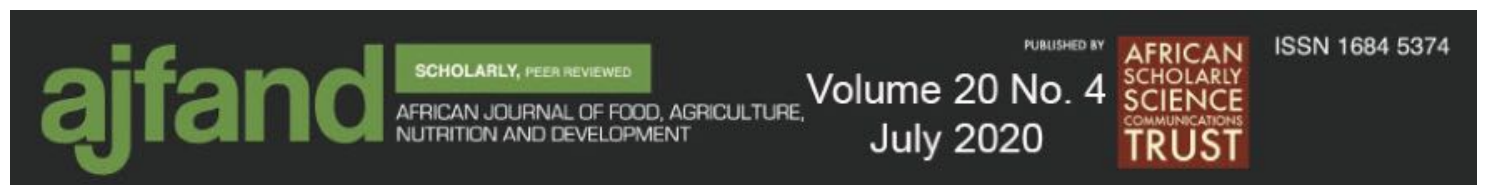

\section{INTRODUCTION}

Couscous is the most famous traditional dish of the Maghreb people (North Africa) [1]. Its consumption has over the last couple of decades had a global reach. Couscous is produced by wet granulation of semolina [2].

Traditional couscous production requires a large workforce. The process involves mixing water and durum wheat semolina in a large wooden dish, then rubbing the mixture between the palms of the hands to form agglomerates or small irregularly shaped granules. The granules are then separated by a set of appropriate sieves and the desired portion retained. The next step is pre-cooking with water vapor, followed by drying in the open [3].

The industrial process of manufacturing couscous from durum wheat semolina includes various processing steps. The agglomeration of the semolina particles is carried out during the wetting, mixing and rolling stages leading, respectively to combination, increase and densification of the granules. This is followed by a steam pre-cooking stage, the objective of which is the gelatinization of the starch. In these stages, the initial semolina particles are wet on the surface where a thin layer of liquid is formed. During collisions between wet particles, capillary forces lead to their assembly through the formation of liquid bridges. Once the water has been evaporated, these liquid bridges are then transformed into solid bridges.

Powders are agglomerated in various devices such as high shear mixers [4], drum granulators[5] and fluidized beds[6]. However, little research has been done on the agglomeration of cereal powders. The limited study done so far on couscous production has been mostly limited to equipment and not fluidized beds.

The objective of this study is, therefore, to examine the possibility of granulating semolina grains to produce couscous in a fluidized bed, as the latter has the advantage of generating strong particle movement and intense mixing to increase the size of the granules uniformly throughout the mass used. This study is, particularly, focused on batch granulation.

\section{MATERIALS AND METHODS}

The raw material used for the production of couscous is a medium-size semolina from the Algerian industrial brand Bousbia.

The semolina is moistened by spraying either distilled or everyday water to which a binder has been added: sodium chloride at a concentration of $5 \mathrm{~g} / 1$ or soft wheat flour at a concentration of $10 \mathrm{~g} / 1$.

\section{Characterisation of base particles}

The granulometric distribution of the semolina is done in a CISA model BA-200-N sieve shaker. This is done using the protocol described by Doukani K [7]. A mass of $50 \mathrm{~g}$ of semolina is sieved for 15 minutes with a vibration amplitude of $2.0 \mathrm{~mm}$ using six sieves 


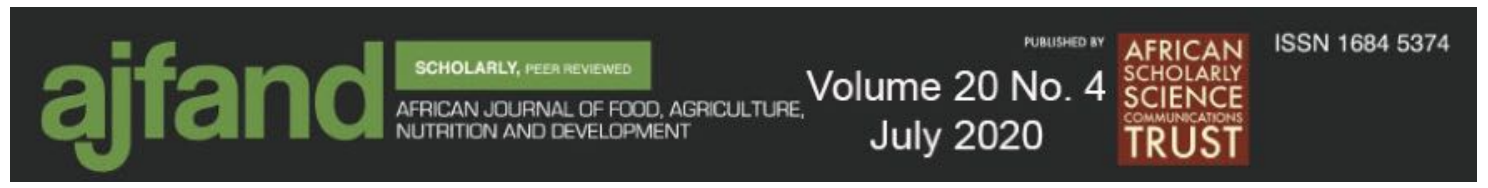

with apertures shown in Table 1 . The results of this process are presented in the same table.

According to Codex Standard 202-1995 established by the FAO (Food and Agriculture Organization of the United Nations), the semolina used contains $77.5 \%$ average semolina, $3.4 \%$ fine semolina and $19.0 \%$ coarse semolina [7]. The average semolina diameter is calculated in the same way as a statistical average when the values are grouped into value classes. The average is calculated using the class centre as follows:

$\overline{d_{p}}=\frac{\sum f \cdot x}{\sum x}$

Where :

$\mathrm{f}$ : is the class centre bounded by the sieve openings.

$\mathrm{x}$ : class mass.

The diameter is calculated as $\overline{d_{p}}=\mathbf{4 5 2 . 8} \mu \mathbf{m}$

A Malvern Mastersizer MS2000 laser granulometer was also used to determine the granulometric properties of the semolina. The results for the characteristic diameters are reported in Table 2 as well as the apparent and actual densities and contact angle determined by the Washburn method [5]. It appears that the average diameters determined by the two methods are relatively similar at an error margin of less than $10 \%$.

Photos of the powder surfaces were obtained using a SEM-EDX scanning electron microscope (Figure 1).

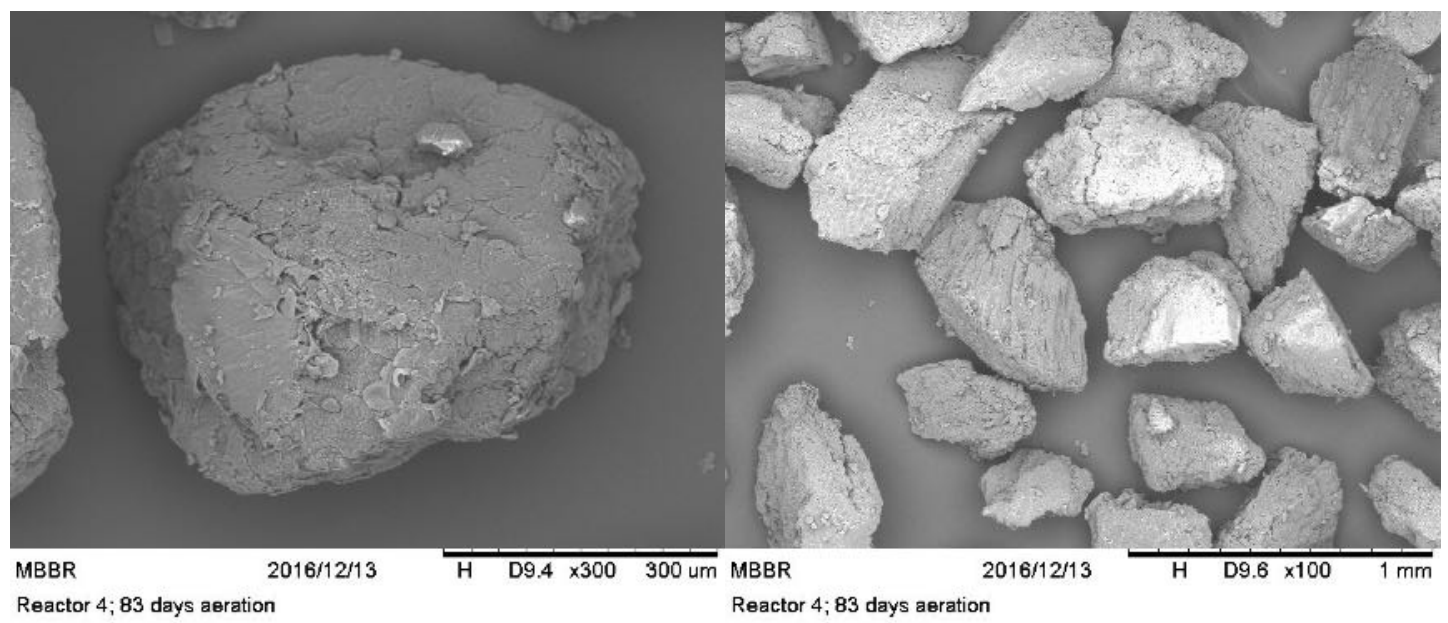

\section{Figure1: SEM photo of the semolina}

The images indicate that the particles have edges, their sizes are inconsistent and that their shapes are not rounded. Zooming in shows that the grain surfaces are rough. In addition, the SEM also provides a mapping of the chemical elements present on the surface(Table 3). 


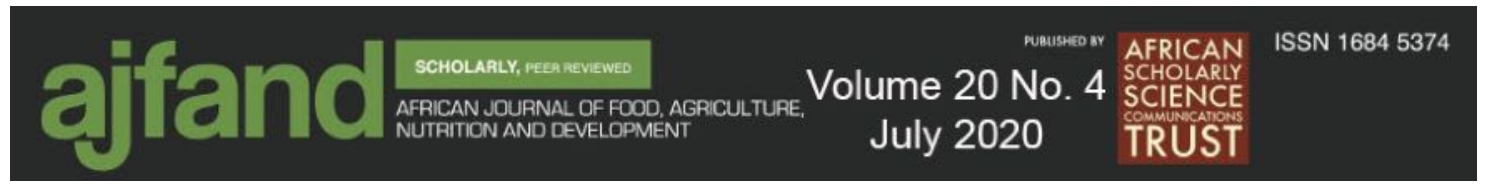

\section{Friability test}

Attrition resistance of agglomerates is a variable that characterizes their ability to be easily handled or compressed and is an important property of the ultimate quality of agglomerates.

There is no one universally agreed method of measuring this. It can be estimated by a friability index which corresponds to the percentage of the powder reduced to a size below a fixed size, for a given period of time using a specific device.

It can be determined by different tests: sieving, rotating drum, impact, fluidization [4].

The shaker shown above was used for the friability test. It consists of placing a certain quantity of couscous in a sieve with an opening smaller than the average diameter of the product. The device is then switched on and intensive sieving is done with an amplitude of $2 \mathrm{~mm}$ for $6 \mathrm{~min}$. This sustained shaking leads to the disintegration of the most fragile granules and the passage of the fine particles formed to the lower screens. Friability is, thus, defined by the mass percentage of couscous lost during the test $(\mathrm{F} \%)$.

$$
\begin{aligned}
& F \%=\frac{\left(m_{i n}-m_{a p}\right) \times 100}{m_{i n}} \\
& \text { Where: } \\
& m_{i n} \text { The intial mass of the couscous grain size. } \\
& m_{a p} \text { Mass of couscous grain size after forced sieving. }
\end{aligned}
$$

The lower the friability index, the higher the mechanical strength of the powder and, hence, the lower the friability.

\section{An overview of the granulator dryer}

The wet agglomeration of semolina is done in a fluidized bed granulator of the brand APPLIED CHEMICAL 100N FLUID-BED shown in the photo in Figure 2 and illustrated in Figure 3.

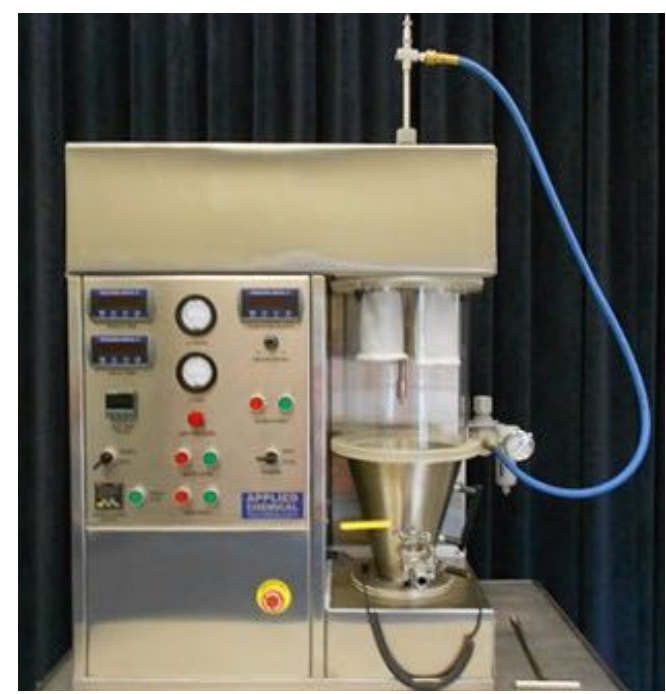

Figure 2: The "100N fluid bed" device

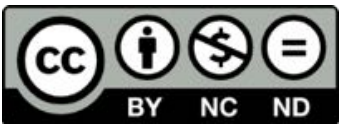



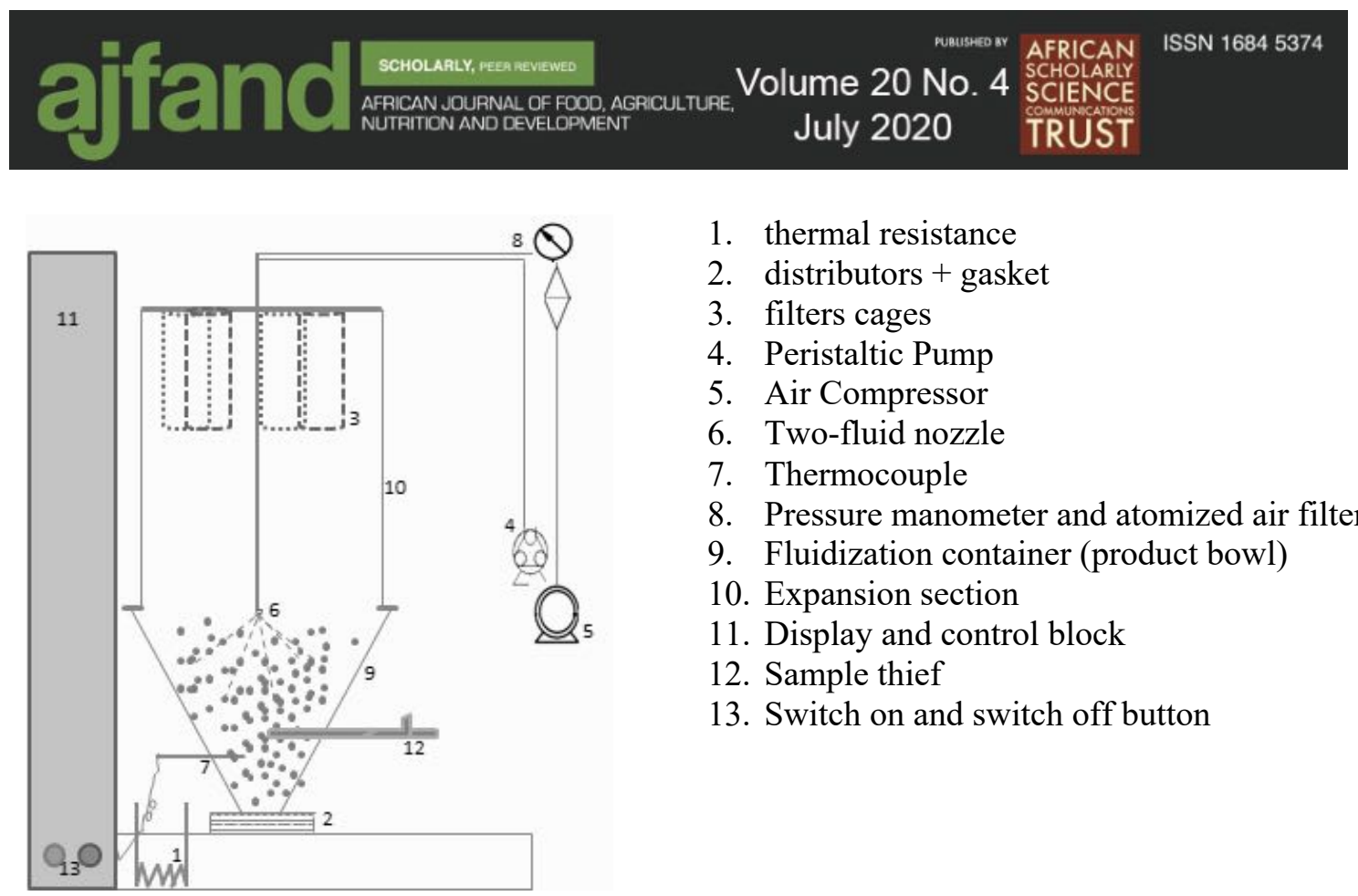

1. thermal resistance

2. distributors + gasket

3. filters cages

4. Peristaltic Pump

5. Air Compressor

6. Two-fluid nozzle

7. Thermocouple

8. Pressure manometer and atomized air filter

9. Fluidization container (product bowl)

10. Expansion section

11. Display and control block

12. Sample thief

13. Switch on and switch off button

Figure 3: Schematic representation of the $100 \mathrm{~N}$ "fluid bed device"

Ambient air is introduced by a variable speed vacuum cleaner controlled by a flow regulator. It passes successively through a resistor (1) to be heated, then through two porous distributors (2) to finally reach the bed. It exits at the top through filters (3) that capture the very fine particles it carries.

On the other hand, a peristaltic pump (4) (Masterflex L/S) allows us to adjust the flow rate of the sprayed liquid. Using a compressor (5), pressurized air is introduced to spray the water from a twin-fluid nozzle (6) placed $10 \mathrm{~cm}$ from the free surface of the bed. The device is also equipped with a display and control system for the various operating parameters of the device. The experimental procedure includes the following steps:

- Filling the steel bowl with the raw material

- Fluidization for 3 minutes at room temperature until the gas injection rate is stabilized

- Switching on the electric heater

- Turning on the air pump and compressor and starting the liquid spraying operation

- After 10 minutes, switch off the unit and recovery of the final product.

\section{RESULTS AND DISCUSSION}

The effects of three types of parameters on the quality of the final product were examined: parameters related to the granulation apparatus (spray air pressure, fluidization air velocity and temperature), parameters related to the sprayed liquid (addition of salt or flour), parameters related to the raw material (proportions of the granulometric classes). The couscous yield formed is measured by the mass fraction of the agglomerated product with the grain size relative to couscous. The agglomerates obtained are classified into three groups: the fine particle class (characteristic size of less 


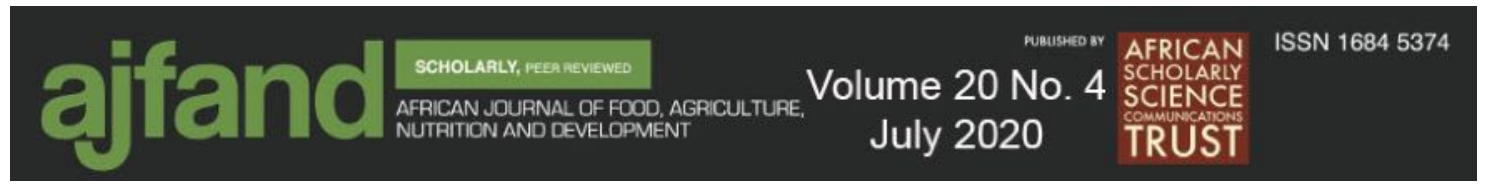

than $0.650 \mu \mathrm{m}$ ), the couscous class (characteristic size of between $0.650 \mu \mathrm{m}$ and $2 \mathrm{~mm}$ ) and the large particle class (characteristic size of more than $2 \mathrm{~mm}$ ).

The air pressure of the spray is set at one bar throughout the experiments. A pressure of less than 1 bar causes wetting of only a narrow part of the bed, resulting in an over-wetted surface, whereas higher pressure leads to a widening of the spray angle and wetting of the container walls (cylindrical section). This causes a considerable amount of semolina to stick to these walls.

\section{Effect of Fluidization Rate}

Fluidization rate is a key determinant of system stabilization [9]. It is also one of the important parameters that determine the growth rate and the granules characteristics since they affect the mixing of the particles, the dispersion of the sprayed binder and the rate of drying [10].

Agglomeration tests were carried out to highlight the influence of fluidization rate on the process efficiency. The rate of fluidization air has been varied between $1.895 \mathrm{~m} / \mathrm{s}$ and $2.596 \mathrm{~m} / \mathrm{s}$. This selection of rate values was based on the fact that below the minimum value, there was a phenomenon of de-fluidization of the bed with formation of large sizes after a few minutes of spraying. However, the increase in the rate of fluidization air resulted in the formation of smaller granules and de-fluidization was delayed. The conditions and the results of all the experiments are presented in Table 4.

The results showed that, at a liquid spray rate and bed temperature of $42.5 \mathrm{ml} / \mathrm{min}$ and $35^{\circ} \mathrm{C}$, respectively, an increase in fluidization rate results in a decrease in the average diameter of agglomerates. This is caused by two phenomena: on the one hand, the increase in the flow of fluidization air causes an increase in the evaporation of the drops of sprayed liquid, which were swept from the bed before they can reach the particles [10], and on the other hand, the intense vibration of the bed causes a rupture phenomenon as a result of forced impacts between the particles.

With respect to the proportion of couscous formed, the results indicate that an increase in fluidization rate initially causes an increase in this proportion, which then stabilizes. Simultaneously, we also observed that the mass of coarse particles decreased while that of the fine particles increased, and then stabilized. This suggests that initially, due to low bed vibration, more of large agglomerates (couscous plus large blocks) are formed. As the fluidization rate increases, the rupture phenomenon intensifies, resulting in a change from the large agglomerate category to the couscous category. At critical velocity, the intensity of inter-particle shocks causes the disintegration of couscous, leading to an increase in the fine particle category.

\section{Effect of liquid flow rate}

The flow rate of the water sprayed was adjusted via a pump. The effect of the liquid flow rate was investigated between $34 \mathrm{ml} / \mathrm{min}$ and $51 \mathrm{ml} / \mathrm{min}$. The spray time was adjusted so that the volume of solution sprayed was always the same. Table 5 shows the operating conditions and test results. 


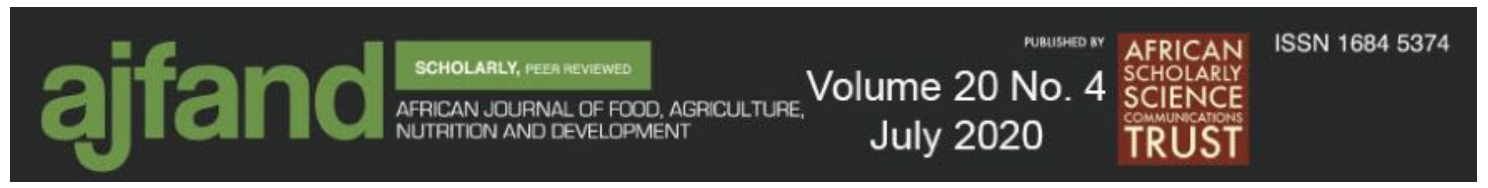

There was no significant agglomeration during the tests, when the spray rate was less than $34 \mathrm{ml} / \mathrm{min}$ for a total quantity of $180 \mathrm{ml}$ of injected water. This observation was reported by Hemati $\mathrm{M}$ et al. [11], where these authors showed that spray rate has no effect on granule formation when it was below a critical value. This suggests that most of the spray water evaporated with the fluidization air. Ormos et al. [12] have defined that liquid flow rates are equilibrated by evaporation, and there is a critical liquid flow rate above which fluidization is impossible due to cohesion in the bed. Usually, a liquid flow between these values is used.

Beyond $34 \mathrm{ml} / \mathrm{min}$, there is an increase in the couscous fraction, followed by a decrease, a continuous increase in the fraction of large agglomerates and a subsequent decrease in the stabilization of the fraction of fine particles. This suggests that the increase in drop size generated by the increase in the flow of water spray and the reduction in the time of the operation led to the emergence of the granulation phenomenon. In addition, at flow rates below $42.5 \mathrm{ml} / \mathrm{min}$, immersion agglomeration is predominant over distribution agglomeration as the proportion of couscous increases while the fine proportion decreases, and that of large agglomerates remain essentially the same at less than $0.5 \%$. On the other hand, at flow rates above $42.5 \mathrm{ml} / \mathrm{min}$, agglomeration by distribution becomes predominant as the coarse proportion increases and the fine fraction stabilizes at around $49 \%$. In fact, according to Saleh K et al. [9], at constant spray air pressure, an increase in liquid flow generates an increase in the size of the drops of sprayed liquid. Obtained results are also in line with those of Schaafsma SH et al. and Seo A et al. [13] and [14], which showed that an increase in drop size implies an increase in granule size. It appears that there is a maximum limit size for liquid drops below which the formation of couscous is predominant.

\section{Effect of temperature}

With the aid of an electrical resistance and thermocouples placed within the fluidized layer and at the bed entrance, the bed temperature was regulated between $22{ }^{\circ} \mathrm{C}$ and $35^{\circ} \mathrm{C}$. Table 6 shows the operating conditions and results of these tests.

This table shows that a temperature increase from 22 to $33{ }^{\circ} \mathrm{C}$ causes a fall in the average diameter of the agglomerates obtained from $1654.84 \mu \mathrm{m}$ to $624.14 \mu \mathrm{m}$, probably because of faster drying.

Moreover, when the bed temperature increases from $22{ }^{\circ} \mathrm{C}$ to $28{ }^{\circ} \mathrm{C}$, the percentage of couscous increases from $26.9 \%$ to $56.8 \%$, while the percentage of large agglomerates drops from $37.2 \%$ to $0.7 \%$. This behavior suggests that at $22{ }^{\circ} \mathrm{C}$, agglomeration by distribution is predominant, thus preferentially generating large agglomerates, whereas when the temperature is increased, the evaporation of the liquid reduces the size of the drops reaching the bed's surface. These sizes then approach the critical threshold, below which granulation by distribution disappears in favor of agglomeration by immersion. At temperatures above $28^{\circ} \mathrm{C}$, there is always agglomeration by immersion, except that the evaporation of liquid drops is greater and the rapid drying of wet particles occurs faster than their bonding, as some authors have reported [12]. These combined phenomena reduce the amount of water reaching the free surface of the fluidized bed, resulting in a reduction in the proportion of agglomerated semolina. 
It should be noted that lumps were formed at lower temperatures (below $22^{\circ} \mathrm{C}$ ) and the bed became de-fluidized. On the other hand, at temperatures above $35^{\circ} \mathrm{C}$, it was observed that the average diameter of $624.14 \mu \mathrm{m}$ was larger than that of the semolina used $(452.88 \mu \mathrm{m})$ but was still smaller than the minimum size required for couscous. This can be explained by the fast drying of liquid before particle collision, which caused little or no granule formation. These findings are similar [16, 17].

\section{Physical aspects of agglomerates}

Using a Scanning Electron Microscope (SEM), pictures of the agglomerates obtained as well as of an Algerian industrial couscous are shown in Figure 4-1. A magnification of these images is also shown in Figure 4-2. Figures A is when sprayed with distilled water, Figures $\mathrm{B}$ is distilled water plus $\mathrm{NaCl}$ and Figures $\mathrm{C}$ is water plus flour. Figures $\mathrm{D}$ is of the industrial couscous.
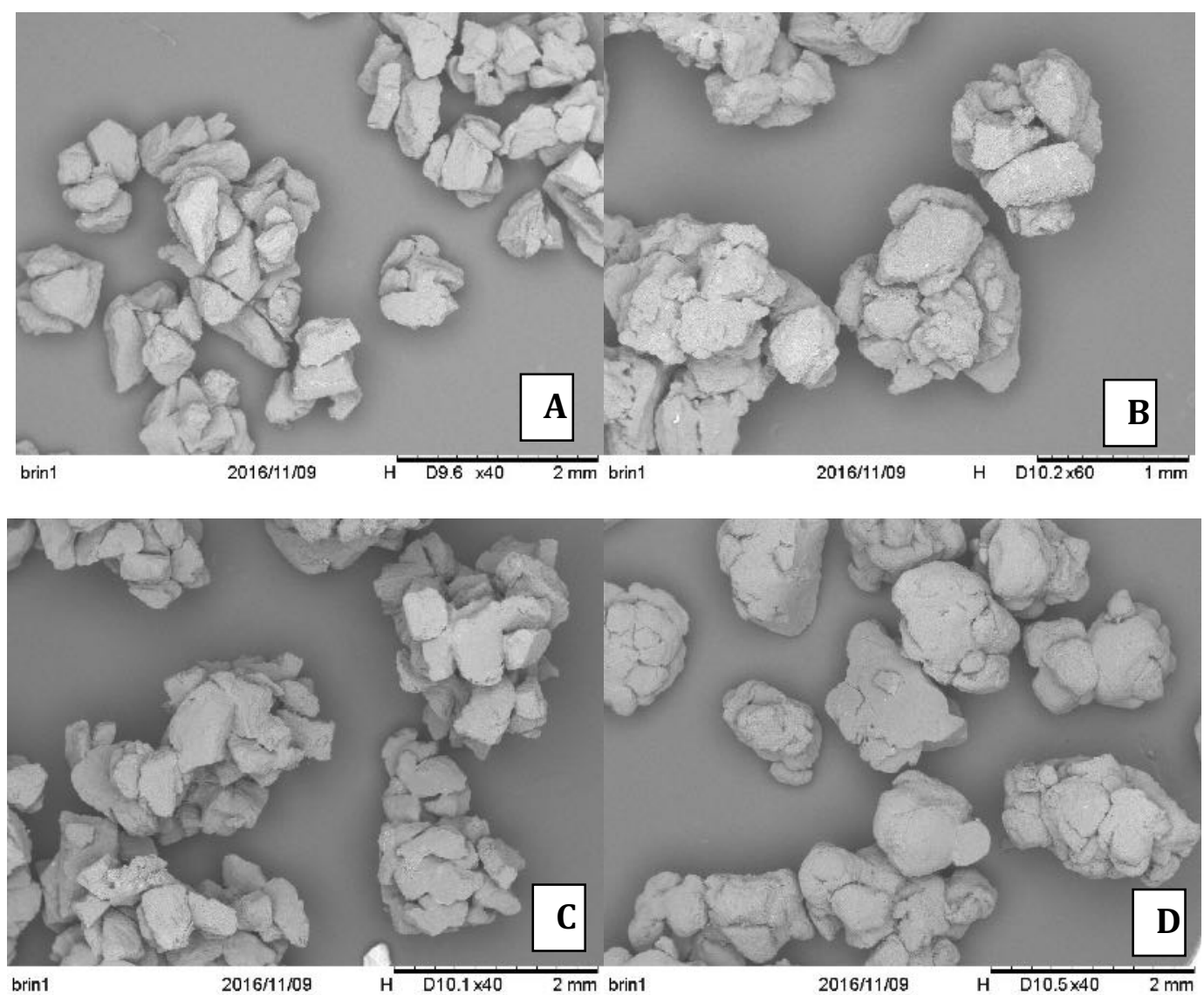

Figure 4.1: SEM photographs of the agglomerates obtained $(A, B, C)$ and for industrial couscous (D) 

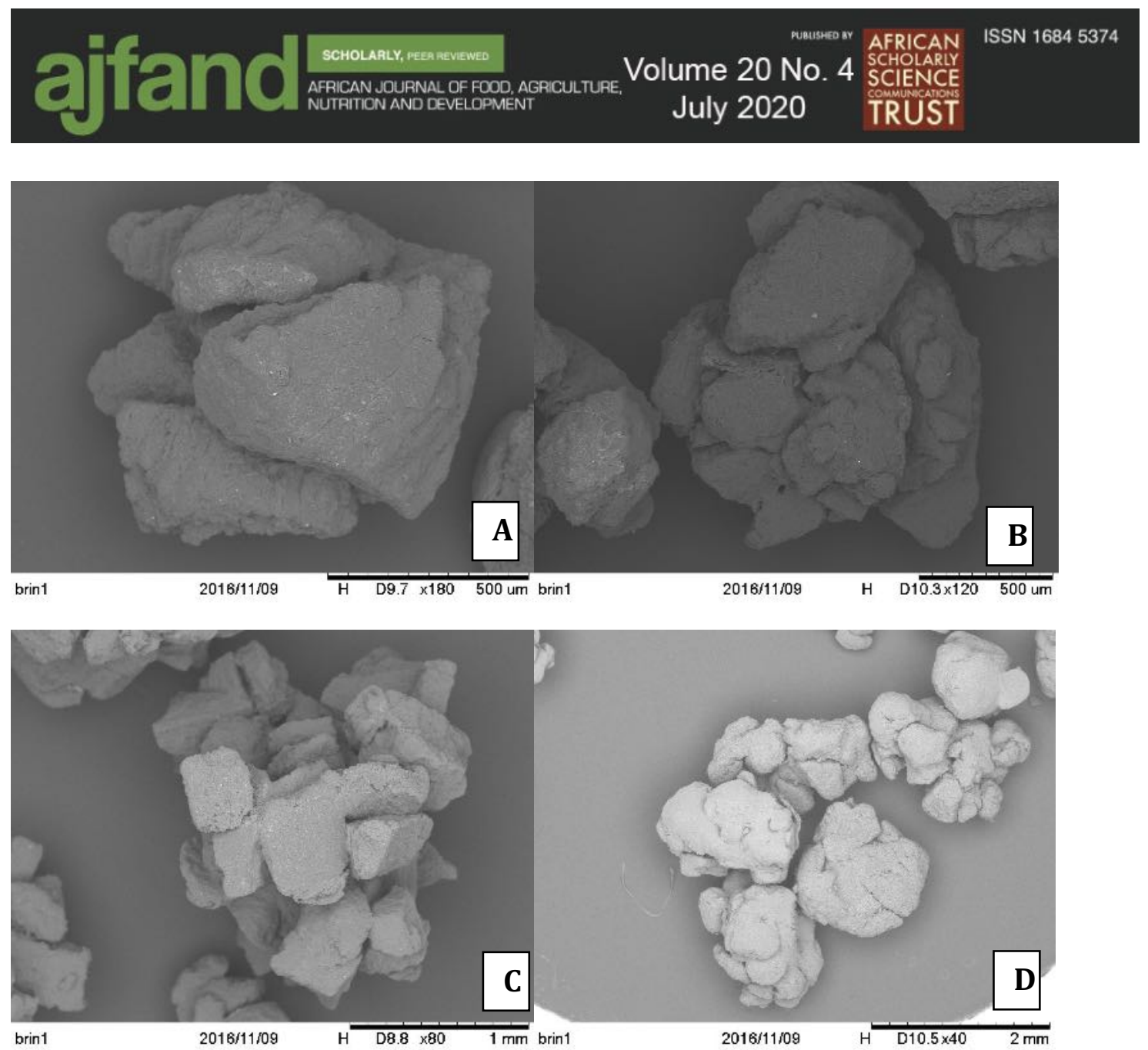

Figure 4.2: Zoomed-in SEM photos of the agglomerates obtained $(A, B, C)$ and for industrial couscous (D)

These photographs of the agglomerates provide valuable insights into the morphology of the agglomerates produced. There is a clear difference in the morphology of the agglomerates produced with those of industrial couscous, particularly with respect to surface shape and roughness. The industrial couscous looks rounder and has a smoother surface. It should be noted that these two criteria are very important for consumers when it comes to choosing among available options. In addition, it appears that granulation with flour in water produces better quality couscous grains.

\section{Effect on couscous friability}

The friability of the couscous produced was assessed through the percentages of disintegrated couscous grains after the vibration process. The experimental results for different tests are grouped in Table 7 . The pre-cooking was carried out by steam for 20 minutes.

An increase in fluidization air velocity from $2.342 \mathrm{~m} / \mathrm{s}$ to $2.596 \mathrm{~m} / \mathrm{s}$ results in a drop in the percentage of friable particles from $27.82 \%$ to $20.83 \%$. This drop is explained by the fact that the couscous grains formed at high rates have already suffered ruptures during their formation, and the process of disintegration of the most fragile has already 


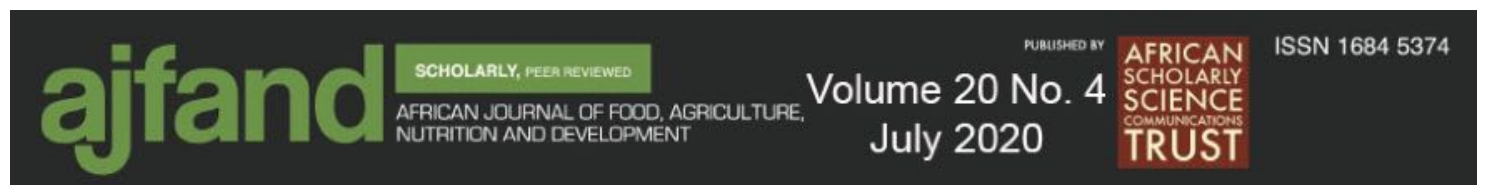

taken place. These grains are, therefore, more compact and resistant than those formed at lower fluidization rates.

In the study by Benali M .[18], it was shown that the friability of dry granules decreased when the rotational speed was increased, thus increasing the movement of the operation chamber, indicating that the granules become stronger as the speed of rotation increased. In addition, the increase in agitation speed favoured the consolidation mechanisms and induced a reduction in porosity [19, 20, 21] and friability rate [19]. As long as the variable friability was directly proportional to the porosity of the granules formed [22], a reduction in porosity induced a decrease in friability.

With respect to the spray water flow rate, the results show that its increase from 42.5 $\mathrm{ml} / \mathrm{min}$ to $51 \mathrm{ml} / \mathrm{min}$ results in a decrease in friability from 20.83 to $12.15 \%$. This is due to the fact that at higher water flows, the droplets have larger sizes wetting the surfaces of the semolina thoroughly and penetrating into its pores. After agglomeration and drying, the solid bridges formed are more resistant. These results are consistent with findings of Munguia MTJ [23]. The friability test results [18] showed a decrease in friability with an increase in flow rates of the binder solution.

As for temperature, we can see that it does not have a significant influence on the friability of couscous. Temperature increase from $22{ }^{\circ} \mathrm{C}$ to $25^{\circ} \mathrm{C}$ reduces the percentage of disintegrated particles during the test from $20.8 \%$ to $17.7 \%$.

Also the addition of $\mathrm{NaCl}$ binders and flour improve the mechanical strength of the agglomerates through the bridges between the particles and also through the filling of the pores between particles as shown in figure 4.1.B.

The hardness must be improved to maintain the properties of the agglomerates during the handling of the powder. This can be done by changing the agglomeration conditions [24]. For example, instead of spraying pure water, a solution of $\mathrm{NaCl}$ or flour could be used to create stronger solid bridges between the particles.

\section{CONCLUSION}

The results of this experimental study showed that the agglomeration of durum wheat semolina for couscous production can be carried out in a small fluidized bed of a spray tube.

The grains formed are quite irregular yet rather compact. The efficiency of the operation was determined by the mass proportion of the couscous formed.

Bed temperature, fluidization rate and spray rate directly influence grain size and therefore the proportion of couscous and process efficiency. Also, adding a small amount of flour to the spray liquid improves the external appearance and reduces the friability of the resulting granules. 


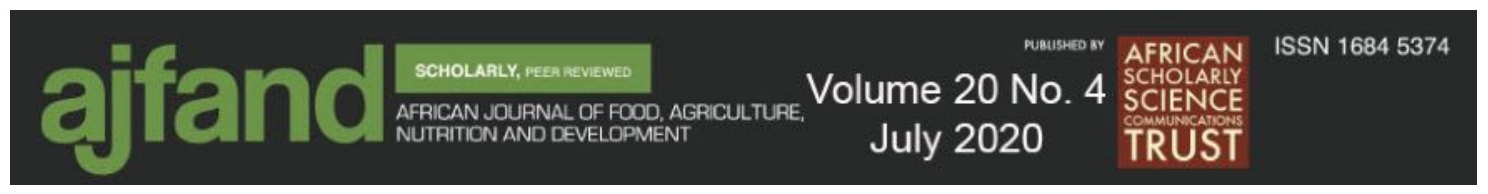

It is recommended for future studies to perform some experiments with row material added with already formed granules to examine whether or not the system behaves like crystallization of salts in supersaturated solutions. If this is so, the added granules act as preferential sites in which agglomeration occurs and the granulation rate will be much faster. Another important parameter to examine is the time of operation.

\section{ACKNOWLEDGEMENTS}

The authors wish to acknowledge the technical support of this study by Professor Mehrdji HEMATI from the National Polytechnic Institute of Toulouse, France. The characterization tests performed in his laboratory were of great help for us. 


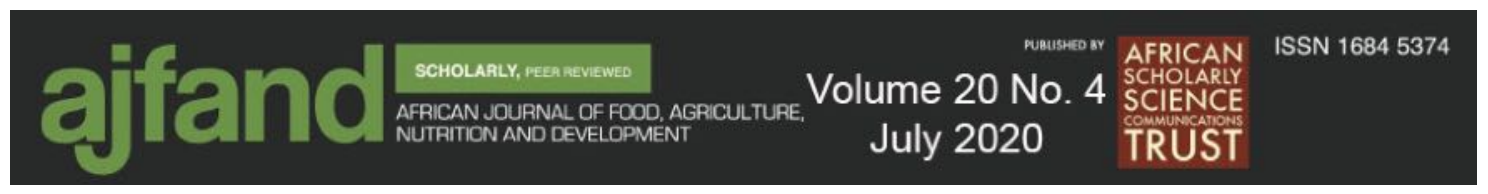

Table 1: The granulometric mass distribution of semolina used

\begin{tabular}{|c|c|c|c|}
\hline Granulometric spread $(\mu \mathrm{m})$ & $125-250$ & $250-500$ & $500-800$ \\
\hline Corresponding mass $(\mathrm{g})$ & 1.9 & 38.7 & 9.7 \\
\hline
\end{tabular}

Table 2: Physical properties of the raw material

\begin{tabular}{|c|c|}
\hline Parameters & Values \\
\hline Actual Density $\left(\mathrm{kg} / \mathrm{m}^{3}\right)$ & 1207 \\
\hline Geldart Classification** & $\mathrm{B}$ \\
\hline $\mathrm{d}_{90}(\mu \mathrm{m})$ & 784.859 \\
\hline $\mathrm{d}_{10}(\mu \mathrm{m})$ & 349.901 \\
\hline $\mathrm{d}(3,2)(\mu \mathrm{m})$ & 499.398 \\
\hline $\mathrm{d}(4,3)(\mu \mathrm{m})$ & 549.711 \\
\hline Isotherme sorption type* & II \\
\hline Apparent density $\left(\mathrm{kg} / \mathrm{m}^{3}\right)$ & 724.2 \\
\hline
\end{tabular}

*Found in Hébrard A et al. [8] , **found in Toumi LB et al. [6]

Table 3: Mapping of chemical elements on the surface

\begin{tabular}{|c|c|c|c|c|}
\hline Carbon & Oxygen & Magnesium & Phosphorus & Potassium \\
\hline 60.896 & 31.635 & 1.761 & 4.253 & 1.455 \\
\hline
\end{tabular}

Table 4: Influence of fluidisation rate on agglomeration of semolina into couscous

\begin{tabular}{|c|c|c|c|c|c|c|c|}
\hline Experiment & $\begin{array}{c}\mathrm{T} \\
\left({ }^{\circ} \mathrm{C}\right)\end{array}$ & $\begin{array}{c}\mathrm{Uf} \\
(\mathrm{m} / \mathrm{s})\end{array}$ & $\begin{array}{c}\mathrm{Q} \\
(\mathrm{ml} / \mathrm{min})\end{array}$ & $\begin{array}{l}\overline{d_{p}} \\
(\mu \mathrm{m})\end{array}$ & $\begin{array}{c}\text { Couscous } \\
\%\end{array}$ & $\begin{array}{c}\text { large particles } \\
\%\end{array}$ & $\begin{array}{c}\text { fine particles } \\
\%\end{array}$ \\
\hline 1 & \multirow[t]{4}{*}{35} & 1.895 & \multirow[t]{4}{*}{42.5} & 1150.03 & 42.2 & 12.504 & 45.288 \\
\hline 2 & & 2.34 & & 1028.21 & 48.9 & 5.16 & 45.93 \\
\hline 3 & & 2.413 & & 938.83 & 46.01 & 2.86 & 51.11 \\
\hline 4 & & 2.596 & & 802.69 & 49.877 & 0.546 & 49.576 \\
\hline
\end{tabular}

Table 5: Influence of spraying flow rate on agglomeration of semolina into couscous

\begin{tabular}{|c|c|c|c|c|c|c|c|}
\hline Experiment & $\begin{array}{c}\mathrm{T} \\
\left({ }^{\circ} \mathrm{C}\right)\end{array}$ & $\begin{array}{l}\text { Uf } \\
(\mathrm{m} / \mathrm{s})\end{array}$ & $\begin{array}{c}\mathrm{Q} \\
(\mathrm{ml} / \mathrm{min})\end{array}$ & $\begin{array}{c}\overline{d_{p}} \\
(\mu \mathrm{m})\end{array}$ & $\begin{array}{c}\text { Couscous } \\
\%\end{array}$ & $\begin{array}{c}\text { Large particls } \\
\%\end{array}$ & $\begin{array}{c}\text { Fine particles } \\
\%\end{array}$ \\
\hline 1 & \multirow[t]{3}{*}{35} & \multirow[t]{3}{*}{2.596} & 34 & 648.66 & 36.65 & 0.373 & 62.973 \\
\hline 2 & & & 42.5 & 802.69 & 49.877 & 0.546 & 49.576 \\
\hline 3 & & & 51 & 1251.63 & 29.064 & 21.442 & 49.493 \\
\hline
\end{tabular}

Table 6: Temperature effect on final product quality

\begin{tabular}{|c|c|c|c|c|c|c|c|}
\hline Experiment & $\begin{array}{c}\mathrm{T} \\
\left({ }^{\circ} \mathrm{C}\right)\end{array}$ & $\begin{array}{c}\mathrm{U}_{\mathrm{f}} \\
(\mathrm{m} / \mathrm{s})\end{array}$ & $\begin{array}{c}\mathrm{Q} \\
(\mathrm{ml} / \mathrm{min})\end{array}$ & $\begin{array}{c}\overline{d_{p}} \\
(\mu \mathrm{m})\end{array}$ & $\begin{array}{c}\text { Couscous } \\
\%\end{array}$ & $\begin{array}{c}\text { Large particles } \\
\%\end{array}$ & $\begin{array}{c}\text { Fine particles } \\
\%\end{array}$ \\
\hline 1 & 22 & \multirow[t]{4}{*}{2.596} & \multirow[t]{4}{*}{42.5} & 1654.84 & 26.967 & 37.236 & 35.976 \\
\hline 2 & 28 & & & 930.28 & 56.777 & 0.73 & 42.494 \\
\hline 3 & 31 & & & 698.55 & 22.659 & 2.008 & 75.332 \\
\hline 4 & 33 & & & 624.14 & 13.092 & 1.435 & 85.471 \\
\hline
\end{tabular}




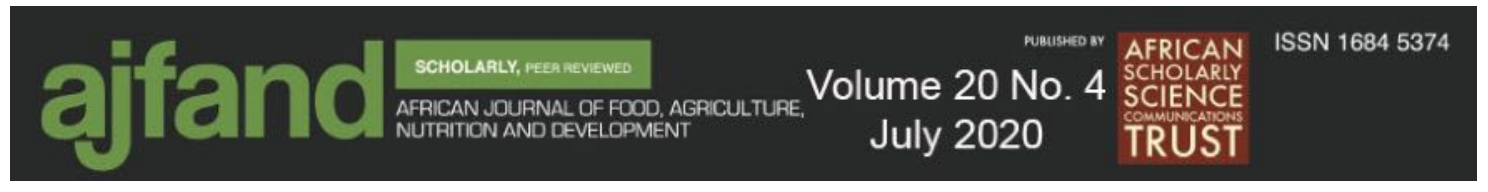

Table 7: Friability of the obtained couscous

\begin{tabular}{|c|c|c|c|c|c|c|}
\hline Experiment & $\begin{array}{c}\mathrm{U}_{\mathrm{f}} \\
(\mathrm{m} / \mathrm{S})\end{array}$ & $\begin{array}{c}\mathrm{Q} \\
(\mathrm{ml} / \mathrm{min})\end{array}$ & $\begin{array}{c}\mathrm{T} \\
\left({ }^{\circ} \mathrm{C}\right)\end{array}$ & $\begin{array}{l}\% \text { decreased } \\
\text { after the test }\end{array}$ & Sprayed solution & Notes \\
\hline 1 & \multirow[t]{2}{*}{2,596} & 51 & \multirow[t]{3}{*}{22} & 12.15 & \multirow[t]{4}{*}{ Distilled water } & \\
\hline 2 & & \multirow[t]{3}{*}{42.5} & & 20.83 & & \\
\hline 3 & 2,342 & & & 27.82 & & \\
\hline 4 & \multirow[t]{4}{*}{2,596} & & 25 & 17.78 & & \\
\hline 5 & & \multirow[t]{3}{*}{51} & \multirow[t]{3}{*}{22} & 10.61 & $\mathrm{NaCl}$ solution $5 \mathrm{~g} / 1$ & \\
\hline 6 & & & & 6.08 & \multirow[t]{2}{*}{ flour solution $10 \mathrm{~g} / 1$} & \\
\hline 7 & & & & 4.94 & & $\begin{array}{l}\text { With pre- } \\
\text { cooking }\end{array}$ \\
\hline
\end{tabular}




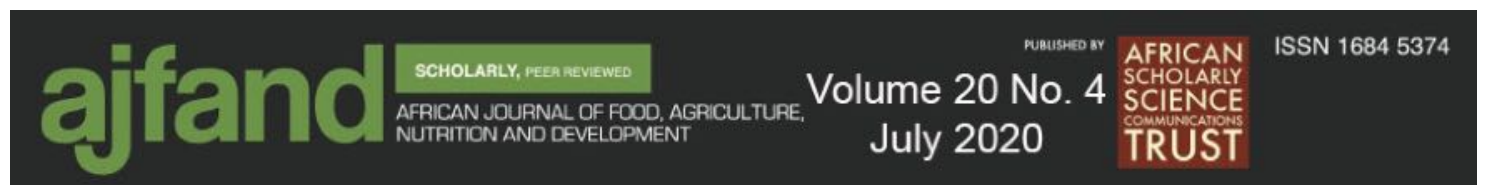

\section{REFERENCES}

$1 \quad$ Kaup SM and CE Walker Couscous in North Africa. Cereal Foods World, 1986; 31: 179-182.

2 Barkouti A Agglomération humide de poudres à réactivité de surface- Approche mécanistique de la morphogenèse de structures alimentaires agglomérées, 2013; $68-82$.

3 Debbouz A and BJ Donnelly Process effect on couscous quality, Cereal Chemistry, 1996; 73(6): 668-671.

4 Benali M Prédiction des interactions substrat / liant lors de la granulation : Etude expérimentale dans un mélangeur à fort taux de cisaillement -Approches thermodynamiques par simulation moléculaire, 2006; 180-200.

5 Ennis BJ, Witt W, Weinekotter R, Sphar D, Gommeran E, Snow RH, Allen T, Raymus GJ and JD Litster Solid Solid operations and processing. In Perry's Chemical Engineers' Handbook 8th edition. Mc Graw Hill, 2008; 21 : 1-147.

6 Toumi LB, Rezzak S and K Allia Wet granulation of cereal grains in a tapered fluidized bed, Chem. Eng. Tran, 2013; 32: 2149-2154.

7 Doukani K Etude comparative entre le couscous industriel et le couscous à base de glands, Nat. Technol. 2015. 2-11.

8 Hébrard A, Oulahna D, Galet D, Cuq B, Abecassis $\mathbf{J}$ and $\mathbf{J}$ Fages Hydration properties of durum wheat semolina: Influence of particle size and temperature, Powder Technol, 2003; 130(1-3): 211-218.

9 Saleh K, Cherif $\mathbf{R}$ and $\mathbf{M}$ Hemati An experimental study of fluidized-bed coating: influence of operating conditions on growth rate and mechanism. Advanced Powder Technology, 1999;10(3): 255-277.

10 Vengateson $\mathbf{U}$ and $\mathbf{R}$ Mohan Experimental and modeling study of fluidized bed granulation: Effect of binder flow rate and fluidizing air velocity, Resour. Technol., 2016; 2: S124-S135.

11 Hemati M, Cherif R, Saleh K and V Pont Fluidized bed coating and granulation : influence of process-related variables and physicochemical properties on the growth kinetics, 2003; 130: 18-34.

12 Ormos ZCB and K Pataki Studies on granulation in fluidized bed. II. The effects of amount of the binder on the physical properties of granule formed in fluidized bed. 1973; 1: 307-328.

13 Schaafsma SH, Vonk P and NWF Kossen Fluid bed agglomeration with a narrow droplet size distribution, 2000; 193: 175-187. 


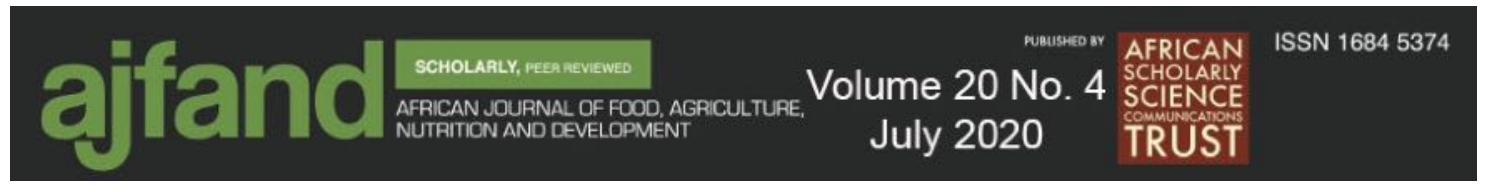

14 Seo A, Holm P and T Schæfer Effects of droplet size and type of binder on the agglomerate growth mechanisms by melt agglomeration in a fluidised bed, 2002; 16: $95-105$.

15 Charinpanitkul T, Tanthapanichakoon W, Kulvanich $\mathbf{P}$ and KS Kim Granulation and tabletization of pharmaceutical lactose granules prepared by a topsprayed fluidized bed granulator, J. Ind. Eng. Chem., 2008; 14 (5): 661-666.

16 Jiménez T, Turchiuli and E Dumoulin Particles agglomeration in a conical fluidized bed in relation with air temperature profiles, 2006; 61: 5954-5961.

17 Davies WL and JTG Walter Batch Production of Pharmaceutical Granulations in a Fluidized Bed II:, J. Pharm. Sci., 1972; 61 (4): 618-622.

18 Benali M, Gerbaud $\mathbf{V}$ and $\mathbf{M}$ Hemati Effect of operating conditions and physico-chemical properties on the wet granulation kinetics in high shear mixer, Powder Technol., 2009; 190(1-2): 160-169.

19 Oulahna D, Cordier F, Galet $\mathbf{L}$ and JA Dodds Wet granulation: The effect of shear on granule properties, Powder Technol., 2003; 130(1-3): 238-246.

20 Saleh K,Vialatte $\mathbf{L}$ and $\mathbf{P}$ Guigon Wet granulation in a batch high shear mixer, Chem. Eng. Sci., 2005; 60(14): 3763-3775.

21 Ohno I, Hasegawa S, Yada S, Kusai K, Moribe K and K Yamamoto Importance of evaluating the consolidation of granules manufactured by high shear mixer, Int. J. Pharm., 2007; 338(1-2): 79-86.

22 Iveson SM Granule coalescence modelling: Including the effects of bond strengthening and distributed impact separation forces, Chem. Eng. Sci., 2001; 56(6): 2215-2220.

23 Munguia MTJ Agglomération de particules par voie humide en lit fluidisé, 2007. 123.

24 Turchiuli C, Fuchs M, Bohin M, Cuvelier M E and C Ordonnaud Oil encapsulation by spray drying and fluidised bed agglomeration, 2005; 6: 29-35. 